Alexander V. Sosnovskiy

Institute of Geography, Russian Academy of Science, 119017, Moscow, Russia,

Staromonetny per., 29. Tel. +7 495 9590035, fax +7 495 9590033,

e-mail:a_sosnovsky@mail.ru

\title{
APPLICATION OF NATURAL COLD FOR PROTECTION OF WATER RESOURCES AGAINST POLLUTION
}

\begin{abstract}
The paper presented herein discusses theoretical and practical aspects of formation artificial firn-ice masses and prospects for their use in solutions of practical and environmental problems. The method utilizes winter sprinkler irrigation with longjet sprinklers. The mass of artificial firm can be as high as 10 meters. This application is effective for treatment and desalination to protect water resources from contamination. Mineralization of artificial firn is $5-10$ times lower than the salinity of the original water. The dynamics of the removal of salts ions, microelements, and dissolved organic compounds during firn melting is assessed through mathematical modeling and experimental research. Melting of one-third of the firn mass decreases mineralization by more than a factor of 10 .
\end{abstract}

KEY WORDS: method of winter sprinkler irrigation (MWSI), contaminated mineralized water, freezing of water, mass of artificial firnice (MAF), desalination, protection of water resources from contamination.

\section{INTRODUCTION}

Protection of natural waters against pollution and desalination of saltwater is a crucial problem. The General Assembly of the United Nations declared the period 2005-2015 the International Decade for Action "Water for Life". One reason for the deterioration of water resources is dumping of waste water of various industries into rivers and lakes. The result is a growing shortage of fresh water and deterioration of its quality, resulting in severe economic and social problems. One of the ways of their solution is desalination and water purification. However, the application of industrial methods of desalination requires large capital and energy investments. Methods of desalination based on the use of renewable natural energy, such as solar radiation and wind, do not produce satisfactory results due to a low density of energy in space and the difficulty of its concentration [Sosnovskiy and Khodakov, 1995]. Therefore, the main problem of finding practically inexhaustible and environmentally friendly forms of natural energy is the development of efficient, economical, and technologically available methods that can be effectively used for the purification and desalination of natural and man-made waters. A promising way of desalination of polluted saltwater in cold regions is the method of winter sprinkler irrigation (MWSI).

\section{FORMATION OF FIRN AND ICE MASSES BY THE METHOD OF WINTER SPRINKLER IRRIGATION}

The use of natural ice for practical purposes has a long history. Artificial freezing is used for the expansion of the scope and efficiency of the application of ice. In Russia, the MWSI for the formation of artificial firn-ice masses has been developed. The method utilizes long-jet sprinklers. Depending on the level of freezing, the method allows obtaining porous ice with the density of $400-600 \mathrm{~kg} / \mathrm{m}^{3}$ and solid ice with the density of $800 \mathrm{~kg} / \mathrm{m}^{3}$. The porous ice is called an artificial firn, since the 


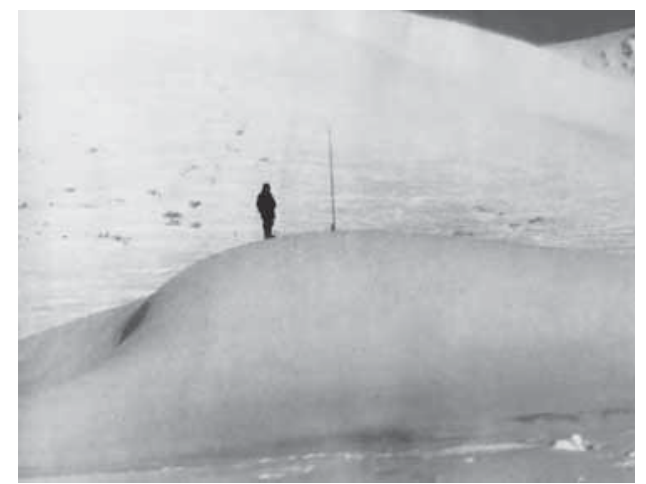

Fig. 1. A $6.7 \mathrm{~m}$ high firn mass with a volume of $2500 \mathrm{~m}^{3}$ is formed after 19 hours of sprinkler DDN-70 work at $-17^{\circ} \mathrm{C}$ air temperature

structure of the porous ice is identical to the firn of a glacier.

The formation of a mass of artificial firn (MAF) occurs when water is sprayed at a height of about 15-20 m. It allows to considerably increase the surface of heat and mass exchange and intensity of freezing and to create a firn thickness of up to 5-10 $\mathrm{m}$ per day with an average density of $500 \mathrm{~kg} / \mathrm{m}^{3}$ (Fig. 1).

The MWSI is widely used in the northern and eastern regions of Russia for the construction of ice crossings. Recommendations for the use of the MWSI for the construction of ice crossings are included in the construction norms and specifications [SNiP 2.02.04-88, 1997].

The maps of the MAF accumulation were compiled in order to estimate the potential volume of MAF within the territory of Russia considering mean air temperatures of below $-5^{\circ} \mathrm{C}$. The following empirical formula was applied in the calculation of the MAF accumulation:

$Q=0,01 G(3 N+1,2|\Sigma T|)$,

where $G$ - flow of water sprinklers, m3/day, $N$ - number of days with an average daily air temperature below $-5^{\circ} \mathrm{C}, \Sigma T$ - the sum of daily mean air temperatures for the period of $\mathrm{N}$ days, ${ }^{\circ} \mathrm{C}$.

The potential formation of ice during the continuous operation of a medium power DDN-70 sprinkler installation during the cold season in Russia is 50-500 thousand tons (Fig. 2).

The artificial firn-ice formations accumulate huge water reserves and natural cold and allow reevaluation of their applicability for the purposes of water supply and for cooling in various industry, energy, and agriculture sectors, which helps saving fuel and energy resources [Sosnovskiy, 1996; Sosnovskiy, 2011].

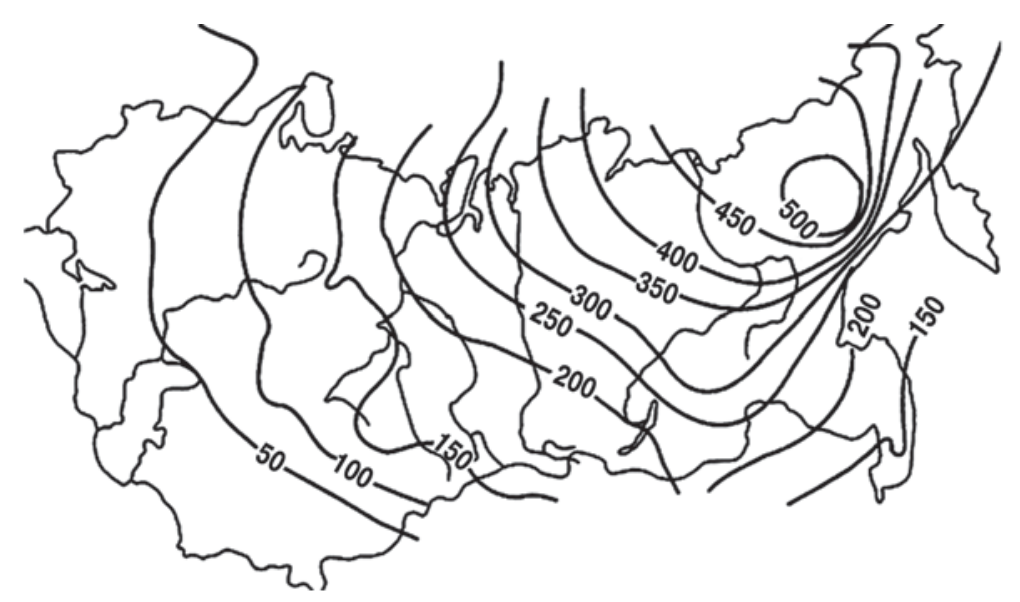

Fig. 2. The potential accumulation of MAF within the territory of the former USSR (for one DDN-70 sprinkler working during cold period, thousand tons) 


\section{THE USE OF MAF IN PROTECTION OF WATER RESOURCES FROM POLLUTION}

Over the last years, several organizations in Russia have developed and tested the MWSI for purification and desalination of polluted mineralized water [Kotlyakov and Khodakov, 1986]. The method is based on the application of long-jet sprinkling installations for spraying, under certain conditions, of polluted mineralized water in cold air and the formation of MAF.

It is known that low intensity freezing leads to the formation of ice with low salinity. Growing ice crystals remove various impurities and salt from the boundary area. At high rates of freezing, salinity nearly coincides with salinity of the water source [Golubev, 1999]. Growing ice crystals capture a large volume of brine. The disagreement between the decrease of salinity of ice and the growth of freezing means that the use of ice for desalination has not found its wide application. This problem has been solved with the use of MAF obtained by the MWSI under specific meteorological conditions [Sosnovskiy, 1987].

Desalination of water by this method occurs during both freezing and melting of MAF. During desalination, the frozen part of the water drops does not exceed 55-60\% of their volume. The water drops become covered with ice crust when they fall out. The ions of salts migrate to the central not frozen part of a drop. During falling out, the ice crust of drops breaks and salt filtrates from the ice. Resulting MAF consists of the fragments of the ice crust and a small amount of salt.

In one hour, more than 100 billion drops are formed. From the fragments of drops, the ice crust is formed in low salinity MAF at a speed of $20-70 \mathrm{~cm} / \mathrm{hr}$. The evaluation of formation and use of MAF included comparison of the results of theoretical modeling of water drops freezing in air with the results of experiments.
The dynamics of salts removal from firn is determined by the intensity of salt exchange during melting. For the calculation of desalination of firn of small thickness during melting, a theoretical dependence of the relative mineralization of firn $-S_{r}$ from its relative mass $-m_{r}$ [Sosnovskiy, 1987] was obtained:

$S_{r}=m_{r}^{\psi}$

where $\psi=(1-f) / f_{;} S_{r}=S_{f} / S_{f 0} ; m_{r}=M_{f} / M_{f 0} ; S_{f 0}$ and $M_{f 0}$ - the initial values of mineralization and the mass of the firn; $S_{f}$ and $M_{f}$ - the current values of mineralization and the mass of the firn during melting; $f$ - the firn moisture, in parts.

The solution of this fomula showed good agreement with the experimental data. Moreover, a similar formula was received during analysis of the experimental results [Sosnovskiy and Gokhman, 2010]. For a more complete accounting of the other parameters of the process, a numerical model that allowed us to estimate the influence of different factors on the efficiency of desalination was developed [Sosnovskiy, 2003]. The intensity of the removal of salts from artificial firn-ice decreases with increasing size of the ice grains, intensity of melting, and water content of artificial firn.

\section{EXPERIMENTAL RESEARCH OF DESALINATION BY THE MWSI}

In order to establish the laws of the desalination process of the formation of artificial firn-ice masses, validation of theoretical positions and assessment of the impact of various factors on the intensity of desalination wereconducted in thelaboratory and field experiments. The experimental results confirmed the theoretical conclusions about the negative impact of the increase of the intensity of melting, the ice grain size, and water content on the efficiency of desalination. The experiments indicated that firn mineralization is 12 times lower than that of the original water source. The remaining salts are removed from firn during 
Table 1. Mineralization of water and firn

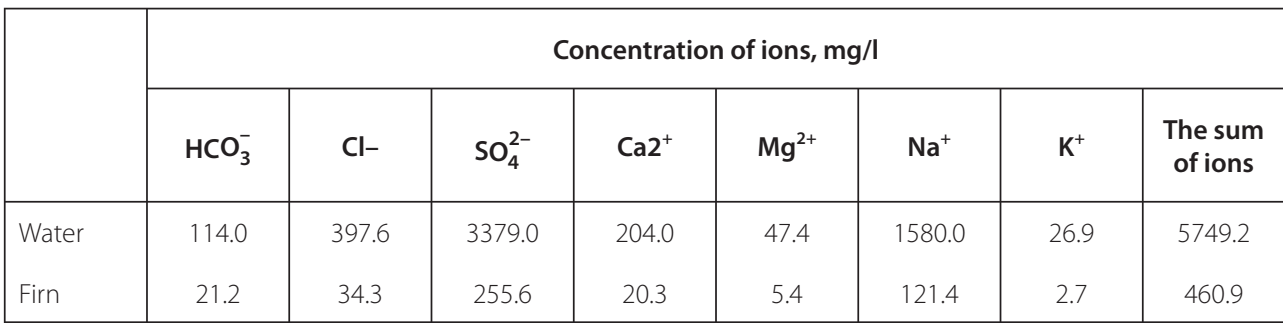

Table 2. Decrease of salts ions concentrations in artificial firn during melting compared with their concentrations in the original water

\begin{tabular}{|c|c|c|c|c|c|c|c|c|}
\hline $\begin{array}{c}\text { Not melting } \\
\text { part of firn }\end{array}$ & $\mathbf{H C O}_{\mathbf{3}}^{-}$ & $\mathrm{Cl}^{-}$ & $\mathbf{S O}_{\mathbf{4}}^{2-}$ & $\mathbf{C a}^{2+}$ & $\mathbf{M g}^{2+}$ & $\mathbf{N a}^{+}$ & $\mathbf{K}^{+}$ & $\begin{array}{c}\text { Sum } \\
\text { of ions }\end{array}$ \\
\hline 0.75 & 8 & 86 & 103 & 35 & 48 & 103 & 43 & 79 \\
0.50 & 9 & 733 & 1302 & 61 & 75 & 900 & 308 & 284 \\
\hline
\end{tabular}

melting. In a series of experiments, water with mineralization of about $6 \mathrm{~g} / \mathrm{l}$ was used. Resulting mineralization of firn decreased by approximately factor of 10 compared with the original water (Table 1).

During melting of one-third of the volume of the artificial firn mass, its salinity decreased by more than a factor of ten (Fig. 3).

Thus, the overall mineralization of the MAF decreased by more than 100 times relative to the initial salinity of water. The residual brine can be reused for the next cycle of freezing and desalination. The use of the MWSI for the creation of large MAF allows one to solve environmental problems in cold regions, such as restoration of contaminated saline ponds and lakes, temporary freeze of accidental discharges of contaminated saline water in emergency situations, creation of ice dams and water storage for water supply purposes, etc. During melting of MAF, desalination and purification of insoluble impurities, dissolved organic matter, microelements, and salt ions occur. The intensity of the removal of salts, microelements, and dissolved organic matter are equally high [Vostokova et al., 1993].

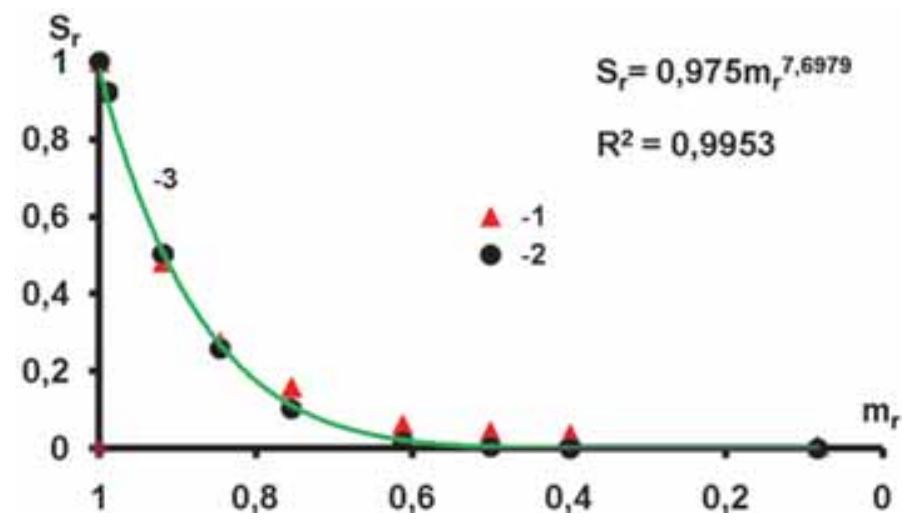

Fig. 3. The dependence of $S_{r}$ from $m_{r}$ :

$a$ - experimental data; $b$ - calculations by the formula (2) for water content of the firn $11 \% ; c$ - $a$ trend at $0,8<m_{r}<1,0$ 
The results of measurements indicated (Table 2) that the dynamics of desalination of firn for individual ions can differ considerably. Thus, ions $\mathrm{Na}, \mathrm{Cl}$, and $\mathrm{SO}_{4}$, microelements, and dissolved organic matter are washed away more intensely than ions $\mathrm{Mg}, \mathrm{K}$, and Ca [Vostokova et al., 1993; Sosnovskiy and Gokhman, 2010]. The least intensity is associated with the hydrocarbonaceous ion.

During melting, insoluble impurities are concentrated at the surface of the formation and do not fall out in meltwater.

\section{CONCLUSION}

The application of the MWSI allows one to quickly create a large volume of artificial firn. This method provides for the effective use of reserves of cold surface air for the formation of artificial firn-ice masses. One sprinkler during a cold season can create MAF with the weight of more than hundred thousand tons. Theoretical and experimental research of various aspects of ice formation and laboratory and field experiments carried out with the use of saline water of different origin showed that the method of creation of artificial firn-ice masses is effective for desalination and purification of contaminated saline water and can be used in protection of water resources from pollution and for their recovery. The mineralization of processed water is hundred times lower than that of the original water.

\section{REFERENCES}

1. Construction norms and specifications. (SNiP 2/02/04-88). (1997). Foundations on permafrost soils / Russian Ministry of Construction. M.: GYP TSPP. 1997. 52 p

2. Golubev V.N. (1999). The structural glaciology. Fundamentals of congelation ice formation.Moscow State University, 104 p.

3. Kotlyakov V.M., Khodakov V.G. (1986). On the prospects of utilizing snow-and-ice resources. Data of glaciological studies, N 56, pp. 140-144 (In Russian with English summary).

4. Sosnovskiy A.V. (1987). Peculiarities of the desalting of salt waters in the course of spraycone freezing of ice. Data of glaciological studies, N 61, pp. 143-149 (In Russian with English summary).

5. Sosnovskiy A.V. (1996). Method of spray-cone freezing of ice application to the water supply handling in different environmental and climatic conditions. Data of glaciological studies, N 80, pp. 163-166 (In Russian with English summary).

6. Sosnovskiy A.V. (2003). Numerical modeling of mass transfer on mineralized and porous ice melting. Data of glaciological studies, N 94, pp. 71-74 (In Russian with English summary).

7. Sosnovskiy A.V. (2011). Artificial firn-ice bodies and the prospects for their use to protect water resources from pollution. Ice and snow, N 2 (114), pp. 135-142 (In Russian with English summary).

8. Sosnovskiy A.V., Gokhman V.V. (2010). Experimental studies on desalination of porous ice. Ice and snow, N 2 (110), pp. 118-126 (In Russian with English summary). 
9. Sosnovskiy A.V., Khodakov V.G. (1995). Artificial ice formation in natural conditions for handling environmental problems. Data of glaciological studies, N 79, pp. 3-6 (In Russian with English summary).

10. Vostokova T.A., Gokhman V.V., Sosnovskiy A.V. (1993). Clearing of natural and technogenic waters of industrial admixtures and micro-elements by way of spray-cone freezing. Data of glaciological studies, N 76, pp. 134-138 (In Russian with English summary).

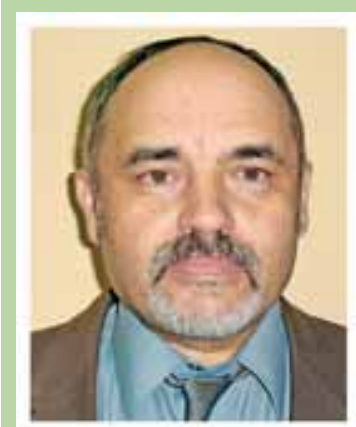

Alexander V. Sosnovskiy, Doctor of Geographical Sciences, graduated from the Mathematical-Mechanical Faculty of the Leningrad State University (1975) and has been working at the Institute of Geography of the RAS since 1978. His main scientific interest relates to making, functioning, and using of artificial firn and ice masses for the solution of engineering and environmental problems; heat and mass exchange during ice formation; thermal physics of snow cover; and heat exchange in the system atmosphere - snow cover - soil. 